\title{
EL IDEALISMO PENAL KANTIANO Y SU RELACIÓN CON EL LLAMADO DERECHO DE LAS VÍCTIMAS AL CASTIGO DE LOS CULPABLES
}

\author{
KANT'S PUNITIVE IDEALISM AND ITS RELATION TO \\ THE SO-CALLED VICTIM'S RIGHT TO RETRIBUTION
}

\begin{tabular}{|c|c|}
\hline \multicolumn{2}{|c|}{ ARTÍCULO INÉDITO DE INVESTIGACIÓN } \\
\hline CÓMO CITAR ESTE ARTÍCULO (CHICAGO) & 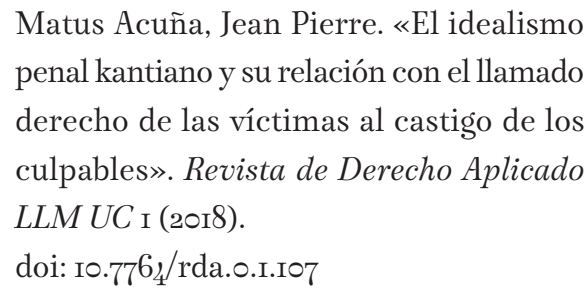 \\
\hline REVISTA DE DERECHO APLICADO LLM UC & $\begin{array}{l}\text { Número I } \\
\text { Julio } 2018 \\
\text { ISSN: } 245^{2-4344}\end{array}$ \\
\hline & $\begin{array}{l}\text { Recepción: } 2 \text { de mayo, } 2018 \\
\text { Aceptación: } 6 \text { de julio, } 2018\end{array}$ \\
\hline
\end{tabular}




\section{Resumen}

$\mathrm{El}$ artículo sostiene la tesis de que el actual punitivismo basado en el supuesto derecho de las víctimas al castigo del culpable puede fundamentarse filosóficamente en el idealismo kantiano y su pretensión de hacer justicia como un imperativo categórico, no sujeto a limitaciones como el principio de legalidad y otros derechos constitucionales, propios del sistema de derecho penal de los estados liberales y democráticos.

Palabras clave: Kant, retribucionismo, punitivismo, víctimas, derechos fundamentales

\section{Abstract}

This article supports the thesis that current punitivism, based on the supposed right of the victims to retribution can be based philosophically on Kantian idealism and its claim to do justice as a categorical imperative, without being subject to such limitations as the principle of legality and other constitutional rights claimed by the criminal law system of liberal and democratic states.

Keywords: Kant, retributionism, punitivism, victims, fundamental rights 


\section{Jean Pierre Matus Acuña}

Universidad de Chile

Facultad de Derecho

Santiago, Chile

jpmatus@derecho.uchile.cl
Jean Pierre Matus Acuña es Profesor Titular de Derecho Penal de la Universidad de Chile, Doctor en Derecho por la Universidad Autónoma de Madrid, becario postdoctoral de la Fundación Alexander von Humboldt en la Universidad de Gotinga (Alemania) y autor de numerosos libros y textos de su especialidad, incluyendo el Manual de Derecho Penal Chileno, Parte Especial, escrito en coautoría con la Profesora María Cecilia Ramírez Guzmán, publicado por la Editorial Tirant Lo Blanch (2 $2^{\mathrm{a}}$ Ed., 2018).

Jean Pierre Matus Acuña is a full professor of criminal law at the Universidad de Chile, Ph. D. (Jur) from the Autonomous University of Madrid, postdoctoral fellow of the Alexander von Humboldt Foundation at the University of Göttingen (Germany) and author of numerous books and texts within his specialty, including the Chilean Criminal Law Manual, Special Section, co-authored by Professor María Cecilia Ramírez Guzmán, published by Tirant Lo Blanch (Valencia, 2nd Ed., 2018). 
¿Cómo se puede explicar que la Corte Interamericana de Derechos Humanos haya llegado a la convicción de que existiría un derecho de la víctima al castigo de los culpables de las graves violaciones a los Derechos humanos y un deber correlativo del Estado a perseguir y sancionar a los culpables, no consagrado en la literalidad de la Convención Americana de Derechos Humanos, pero cuya fuerza, sumada a las exigencias de la justicia, permitiría pasar por alto, mediante el mecanismo de la "ponderación", derechos literal y explícitamente garantizados a todo justiciable como el principio de legalidad (incluyendo la prohibición de la retroactividad) ${ }^{1}$, el derecho a un juicio en un plazo razonable ${ }^{2} \mathrm{y}$ hasta la prohibición del doble enjuiciamiento ${ }^{3}$, como critica Exequiel Malarino ${ }^{4}$ ?

¿Qué significa que los perseguidos de ayer se alcen implacables contra sus perseguidores, celebrando llevar gente a prisión cuando antes ello era visto como opresión estatal, según denuncia Daniel Pastor ${ }^{5}$ ?

¿Qué artilugio retórico permite a la Corte Interamericana de Derechos Humanos alterar el texto del Art. 6.5. del Protocolo II de las Convenciones de Ginebra, para afirmar que al término de un conflicto armado no es posible, en ningún caso, amnistiar a los vencidos como se hizo al término de la ocupación norteamericana de Alemania respecto de criminales nazis ${ }^{6}$ ?

1 Organización de Estados Americanos, Convención Americana sobre Derechos Humanos, "Pacto de San José", 7-22 noviembre ig69, art. 9 .

2 Organización de Estados Americanos, Convención Americana sobre Derechos Humanos, "Pacto de San José”, 7-22 noviembre ig69, art. 8.I.

3 Organización de Estados Americanos, Convención Americana sobre Derechos Humanos, "Pacto de San José", 7-22 noviembre ig69, art. 8.4.

4 Exequiel Malarino, "Activismo judicial, punitivización y nacionalización. Tendencias antidemocráticas y antiliberales de la Corte Interamericana de Derechos Humanos“, en Sistema interamericano de protección de los derechos humanos y derecho penal internacional, ed. por Gisela Elsner, (Montevideo: Konrad Adenauer Stiftung, 20I0), 25-62; y especialmente, ${ }_{45}^{-4} 8$, donde denomina a este fenómeno como una tendencia hacia la "punitivización” de la Corte.

5 Daniel Pastor, "El derecho penal del enemigo en el espejo del poder punitivo internacional”, en Derecho Penal del enemigo. El discurso penal de la exclusión, vol.2, ed. por Manuel Cancio Meliá y Carlos Gómez-Jara Díez, (Madrid: Edisofer, 2006), 475-522.

6 Jean Pierre Matus Acuña, "Informe sobre la ejecución de la sentencia en el caso Almonacid presentado a la Cámara de Diputados", Revista Ius et Praxis ı2, no 2 (2006): 385-396. Aquí se distingue entre los casos en que la amnistía es admisible al término de las hostilidades y aquéllos en que no se admite por constituir, básicamente, autoamnistías, distinción que no hace la Corte Interamericana de Derechos Humanos. 
¿Cómo se explica que la Oficina del Fiscal de la Corte Penal Internacional haya presentado un escrito de Amicus Curiae ante la Corte Constitucional de Colombia señalando que el acto legislativo que implementa el proceso de paz en ese país «podría frustrar los esfuerzos de Colombia por cumplir sus obligaciones de investigar y juzgar los crímenes internacionales» ${ }^{7}$, sugiriendo implícitamente que no se implemente la paz para cumplir con esas obligaciones respecto del concepto de responsabilidad del superior, contrariando así los propósitos declarados de las Naciones Unidas, esto es, «mantener la paz y la seguridad internacionales y fomentar el respeto de la libre determinación de los pueblos para tomar medidas adecuadas para fortalecer la paz universal» ${ }^{8}$ ?

La tesis que aquí se defiende es que esta mutación en el concepto de los derechos humanos en materia penal desde la defensa de los derechos de los justiciables a la del derecho de castigar de las víctimas, puede explicarse por la evolución social y cultural del cambio de siglo, la que - en el ámbito de la filosofía del castigo- puede encontrar una justificación $a d$-hoc en el renacimiento del idealismo kantiano.

En efecto, desde el punto de vista de la evolución social y cultural del cambio de siglo en lo que respecta al Derecho Penal, desde diferentes perspectivas se ha consolidado la idea de que la solución a los problemas de convivencia actuales pasa por el castigo de quienes se consideran responsables de los mismos. Éste es el proceso que se ha descrito críticamente como expansión del Derecho Penal ${ }^{9}$, huida hacia el Derecho Penal ${ }^{10}$, populismo penal ${ }^{11}$ y otros conceptos similares.

Según la visión crítica de este proceso, esta expansión o huída se produciría por la intervención de defensores más o menos explícitos de intereses económicos en el origen de nuevas reglas penales, burocracias internacionales dependientes (por ejemplo, la UNODC), múltiples ONG de protección de víctimas de diversa naturaleza y otros emprendedores morales atípicos interesados que, mediante técnicas de lobby y comunicación estratégica

7 Escrito de amicus curiae sobre la jurisdicción especial para la paz ante la Corte Constitucional de la República de Colombia, Fiscal de la Corte Penal Internacional, Ref.: RPZ-000000I y RPZ-003, * 2I (del I8 de octubre de 20I7) (disponible en http:/croo.epimg.net/ descargables/20I7/ro/2I/I7I35b6o6rc7a5o66ea86fe7e37ce26a.pdf?int=masinfo).

8 Ibid.

9 Jesús Silva Sánchez, La expansión del Derecho penal. Aspectos de política criminal en las sociedades postindustriales, 2a ed. (Buenos Aires: Civitas, 2008), 64-IIO.

10 Raúl Carnevali, “„Es adecuada la actual política criminal estatal?”, en Gaceta Jurídica $24_{4}^{2}$ (2000): 8 , nota 2.

11 John Pratt, Penal Populism (Londres: Routledge, 2007), II. 
en medios masivos, intervendrían para promover los cambios legislativos que buscan y terminan en nuevos delitos, agravaciones de los existentes o reformas en los procedimientos que hagan más fácil su persecución, reduciendo garantías tradicionales del Derecho Penal. El efecto de esta intervención sería un cambio en la perspectiva de las relaciones sociales, pasando a ser considerados los criminales como favorecidos por las leyes frente a víctimas más o menos indefensas y desprotegidas. Esto llevaría a una revalorización de los riesgos provenientes de ciertos hechos, como los delitos de carácter sexual vinculados a menores, el tráfico ilícito de estupefacientes, la criminalidad organizada, la corrupción funcionaria, etc., reflejada en un progresivo aumento de los hechos incriminados y las penas disponibles para esa clase de delitos.

Esta evolución no puede, a nuestro juicio, considerarse aisladamente de la revolución cultural de fines del siglo XX, que podemos calificar como de consolidación del neoliberalismo o, en términos generales, de la llamada sociedad de derechos (individuales). Según Hobsbawn, la revolución cultural operada a fines del siglo XX, puede «entenderse como el triunfo del individuo sobre la sociedad o, mejor, como la ruptura de los hilos que hasta entonces habían imbricado a los individuos en el tejido social» ${ }^{12}$, triunfo que habría producido una suerte de «liberalización social generalizada» y creciente «individualismo moral», aparentemente «progresista». Esta ruptura puede verse reflejada, en términos de Hobsbawn, en el debilitamiento de las redes familiares y vecinales; la progresiva liberalización en materias sexuales y el aumento en las demandas por el control de la natalidad, con la correlativa pérdida de influencia de las iglesias occidentales en la conducta real de sus feligreses; el discurso de los "derechos" de cada uno sin atender a los "deberes" que ya no se suponen correlativos; y la pérdida de sensibilidad social manifestada en la creciente tendencia social a rechazar el tratamiento y la comprensión frente a quienes cometían delitos, pidiendo, en cambio, sencillamente que se castigase a los antisociales ${ }^{13}$.

En consecuencia, al establecerse la idea de que existiría un derecho fundamental de las victimas a castigar ( por medio del Estado), la impunidad aparece como una violación a un derecho humano y a las obligaciones de los Estados a su promoción y respeto, frente a la cual no pueden oponerse con éxito las limitaciones a la actividad del Estado reconocidas por el Derecho Internacional frente a los justiciables, como el derecho al debido proceso y a recibir una pena que ofrezca oportunidades de resocialización y no un mero castigo.

12 Erich Hobsbawn, Historia del Siglo XX, I० ${ }^{\mathrm{a}}$ ed. (Buenos Aires: Crítica, 201I), 336-345.

13 Ibid. 
Como anticipamos, a nuestro juicio, esta idea de que la justicia de las víctimas prevalece sobre las garantías del justiciable puede encontrar un fundamento filosófico en el idealismo kantiano.

En efecto, como diría Kant, «cuando la justicia perece, entonces ya no tiene más valor la vida la vida del hombre sobre la tierra» ${ }^{14}$. Luego, desde este punto de partida, alguien bien puede afirmar que hacer justicia es un imperativo categórico y, en ese sentido, no sujeto a restricciones, como las derivadas de tecnicismos o derechos procesales de los justiciables, o las necesidades de rehabilitación, la mera compasión, limitaciones técnicas o materiales de menor entidad. Todas éstas son incompatibles con la categórica necesidad de hacer justicia para dar sentido a nuestra vida en la tierra. Y por eso Kant, tan poco dado a citar a terceros, sí cita a Beccaria para rechazar el principio de legalidad y las limitaciones que éste propone a la pena de muerte, señalando que el recurso a la teoría del contrato social para limitar el poder punitivo sería solo «sofistiquería y torcicería del derecho» y que las restricciones a la pena de muerte se basarían en «sentimentalismo y afectada humanidad (compassibilitas)» ${ }^{15}$.

Claro que se cuida Kant de no darnos muchos ejemplos de lo que es justo en sí mismo, salvo dar muerte al homicida bajo la regla "ojo por ojo, diente por diente", según el Talión, pues en tal caso «no existe ningún otro subrogado para la satisfacción de la justicia» ${ }^{16}$.

Este punto de partida kantiano es una base filosófica que bien puede permitir a los grupos de familiares de víctimas de violaciones a los derechos humanos celebrar la muerte de los victimarios en prisión y oponerse a que sean indultados aun cuando se encuentren privados de razón o con una enfermedad terminal.

Y si se considera verdadero que en el límite del argumento, cuando se debe decidir entre una cosa u otra, el imperativo categórico de hacer justicia, esto es, imponer una pena, se sobrepone a toda consideración humana, de política criminal o, incluso, de garantías constitucionales (que Kant desconocía en su concepto moderno), entonces es también verdad que la «despedida en Kant y Hegel» anunciada en Ig68 por Klug -al valorar el

\footnotetext{
14 Immanuel Kant, Die Metaphysik der Sitten. Vol.6, Akademieausgabe (I797),

http://www.korpora.org/kant/aao6, $33^{2}$.

15 Ibid., 335

16 Ibid., 333
} 
Proyecto Alternativo de los Profesores de Derecho Penal, que declaraba la pena una «amarga necesidad» en el mundo real, no vinculada a pretensiones metafísicas - fue una despedida «en falso» ${ }^{17}$.

Y ello, a pesar de que las pretensiones de "justicia" o "necesidad" para el "restablecimiento del derecho" de la imposición de una pena, o el supuesto carácter de "imperativo categórico" del derecho penal, han sido consistentemente rechazadas no sólo por la filosofía alemana no idealista posterior al siglo XVIII, como puede verse en Schopenhauer ${ }^{18} \mathrm{y}$ Nietzsche ${ }^{19}$, sino también por otros pensadores idealistas, como Platón, quien quizás

17 Jean Pierre Matus Acuña, La transformación de la teoría del delito en el derecho penal internacional (Barcelona, Atelier, 2008), 69. Según Ulrich Klug, "Abschied von Kant und Hegel”, en Programm für ein neues Strafgesetzbuch. Der Alternativ-Entwurf der Strafrechtslehrer, ed. por Jürgenn Baumann (Frankfurt am Main: Fischer, I960), 39-4o, para quien las teorías penales de estos filósofos idealistas no estarían en ningún caso probadas por ellos y sus seguidores, "sino simplemente proclamadas", esto es, ellas no se constituirían como un un "conocimiento" (Erkenntnis), sino como una "proclamación” o "artículo de fe" (Bekenntnis). En el caso del planteamiento de Kant, afirma Klug que no existiría un argumento para negar la "justicia" de una pena útil en vez de una puramente retributiva, y que el "imperativo categórico" no sería más que un concepto vacío, «pues la pregunta, a qué clase de ley general debiera referirse, permanece abierta», y «podría valer, en todo caso, incluso en una pandilla de Gangsters», por lo que, siendo «un principio vacío», de él «no se puede extraer ningún contenido, no se puede deducir el principio de retribución». Y con respecto del pensamiento de Hegel, el argumento de que la pena es la negación del delito puede calificarse, según Klug, de "pseudo-lógico", pues en ningún modo resulta lógicamente obligatorio, ya que bien puede decirse lógicamente que la «violencia es aumentada por la violencia», o que «la violencia es anulada por la noviolencia», al mismo tiempo que la frase que afirma que la pena es «la negación de la negación» del Derecho por el delito no sería más que «una metáfora y, más encima, confusa», esto es, sólo «una estructura del habla y no de los hechos objetivos».

18 Arthur Schopenhauer, Die Welt als Wille und Vorstellung, (Frankfurt am Main: Cotta, 1960), 475-477. Según éste, la ley positiva, basada en el contrato social, «para evitar el delito, le prescribe una pena, cuya amenaza debiera operar como contramotivo de todos los otros motivos que llevan al delito» (475). Esta finalidad «hacia el futuro» es lo que «diferencia la pena de la venganza» (476). Por ello, resulta "infundado" el planteamiento de Kant, a pesar de la «vacía palabrería» con que se adorna cuando se reproduce en los «escritos de los profesores de derecho» $\left({ }_{47} 6\right)$, pues «retribuir el mal con otro mal sin ulterior finalidad no es moral ni tiene ningún fundamento racional para su justificación, y poner al ius talionis [derecho a la retribución] como principio final y autosuficiente del derecho penal, carece de sentido» (475), agregando que este rechazo de la pena como venganza y su reemplazo por una pena con finalidad útil no es una novedad, sino que así ha sido planteado tanto por penalistas de su tiempo, como Feuerbach, como por otros filósofos modernos, Puffendorf y Hobbes, por ejemplo, y antiguos, como Platón y Séneca (Ira, I, XIX, 7) de quien cita la frase «nemo prudens punit, quie peccatum est, sed ne peccetur» (477).

19 Ver al respecto Jochen Bung, "Nietzsche über Strafe", Zeitschrift für die Gesamte Strafrechtswissenschaft II9, $\mathrm{n}^{\circ}$. I (2007): I20-I36, doi:I0.I5I5/ZSTW.2007.004, donde se resumen las tesis nietzschianas sobre el origen de la pena y la culpa, su crítica a las teorías clásicas de la pena, su decidido abolicionismo y la forma cómo imagina una sociedad libre del derecho penal. 
pueda estimarse como el filósofo idealista por excelencia, lo que no le impedía identificar el hecho de aplicar castigos únicamente porque se habría cometido un delito como una forma de actuar "irracional", pues

nadie castiga a los injustos con la atención puesta en, o a causa de, que cometieron injusticias, a menos que se vengue irracionalmente como una bestia. El que se pone a castigar con la razón aplica el castigo, no por la injusticia pasada, pues no conseguiría que lo que fue dejase de ser, sino pensando en el futuro, para que ni él ni quien ve su castigo vuelvan a cometer injusticias $^{20}$.

Luego, el gran triunfo de las ideas kantianas es haber transformado la venganza y la simple retribución ciega en la idea de La Justicia y de allí en un derecho humano. Y como sin justicia no tiene sentido la vida del hombre sobre la tierra, tal derecho es preeminente sobre el resto de los intereses sociales, incluidas las garantías de los justiciables, las finalidades resocializadoras de la pena y hasta la paz y seguridad de los pueblos, ya que para una justicia absoluta, las garantías y la paz social que algunos pueblos acuerden democráticamente son bienes relativos que deben sacrificarse para que la sangre de las víctimas no caiga sobre los hombros de quienes dejaron al asesino sin castigo.

Siendo así las cosas, de lo que nos estamos despidiendo no es de Kant y de Hegel, sino del estado nacional soberano, de la democracia deliberativa y del principio de legalidad y de las garantías para los justiciables en los delitos cuyo castigo se considere un derecho humano universal y absoluto. $\square$

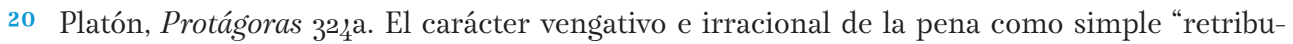
ción” sin mira a la utilidad pública también es destacado por Tucídides en su relato sobre la pena que debían imponer los atenienses a los sublevados en Mitilene, donde Cleón, demagogo de personalidad vengativa y ambiciosa, alega en favor de la muerte de todos los mitilenos adultos y la venta en esclavitud de los niños como castigo "proporcional” a su insurrección. Sobre el texto de Tucídides y las teoría de las penas, ver Ulises Schmill, "El debate sobre Mitilene. Una interpretación”, Doxa, 4 ( 1987$), 203^{-2} 45$. Nótese que esta vinculación entre la pena de muerte como castigo proporcional a la "sublevación" es muy coincidente con el rechazo absoluto a toda rebelión de Kant y su tesis de que la pena de muerte es "lo menos" que debe imponerse al "menor intento" de matar al soberano, aun cuando éste fuese un tirano, en Immanuel Kant, Die Metaphysik der Sitten, vol.6, Akademieausgabe (I797), 320, http://www.korpora.org/kant/aao6. 


\section{BIBLIOGRAFÍA}

- Bung, Jochen. "Nietzsche über Strafe". Zeitschrift für die Gesamte Strafrechtswissenschaft II9, $\mathrm{n}^{\circ}$. I (2007): 120-136. doi:IO.I515/ ZSTW.2007.004

- Carnevali Rodríguez, Raúl. «ZEs adecuada la actual política criminal estatal?». Gaceta Jurídica $24_{4}^{2}$ (2000): 7-12.

- Hobsbawn, Erich. Historia del Siglo XX, 10 ${ }^{\mathrm{a}}$ ed. Buenos Aires: Crítica, $20 I I$.

- Kant, Immanuel. Die Metaphysik der Sitten. Vol.6 de Akademieausgabe, I797. http://www.korpora.org/kant/aao6.

- Klug, Ulrich. "Abschied von Kant und Hegel". En Programm für ein neues Strafgesetzbuch. Der Alternativ-Entwurf der Strafrechtslehrer. Editado por Jürgenn Baumann, ${ }_{36-4}{ }_{4}$. Frankfurt am Main: Fischer, I960.

- Malarino, Exequiel. "Activismo judicial, punitivización y nacionalización. Tendencias antidemocráticas y antiliberales de la Corte Interamericana de Derechos Humanos". En Sistema interamericano de protección de los derechos humanos y derecho penal internacional. Editado por Gisela Elsner, 25-62. Montevideo: Konrad Adenauer Stiftung, 2010 .

- Matus Acuña, Jean Pierre. "Informe sobre la ejecución de la sentencia en el caso Almonacid presentado a la Cámara de Diputados". En Revista Ius et Praxis 12, $\mathrm{n}^{\circ} 2$ (2006): $3^{8} 5^{-} 39^{6}$.

- __ La transformación de la teoría del delito en el derecho penal internacional, Barcelona: Atelier, 2008.

- Pastor, Daniel. "El derecho penal del enemigo en el espejo del poder punitivo internacional”. En Derecho Penal del enemigo. El discurso penal de la exclusión. Vol.2. Editado por Manuel Cancio Meliá y Carlos Gómez-Jara Díez, 475-522. Madrid: Edisofer, 2006. 
REVISTA DE DERECHO APLICADO LLM UC • NÚMERO I • JULIO $20 \mathrm{I} 8$

- Pratt, John. Penal Populism. Londres: Routledge, 2007.

- Schmill, Ulises. “El debate sobre Mitilene. Una interpretación”. Doxa $4(1987): 203-245$.

- Schopenhauer, Arthur. Die Welt als Wille und Vorstellung. Frankfurt am Main: Cotta, ig6o.

- Silva Sánchez, Jesús, La expansión del Derecho penal. Aspectos de política criminal en las sociedades postindustriales, 2.a ed. Buenos Aires: Civitas, 2008. 